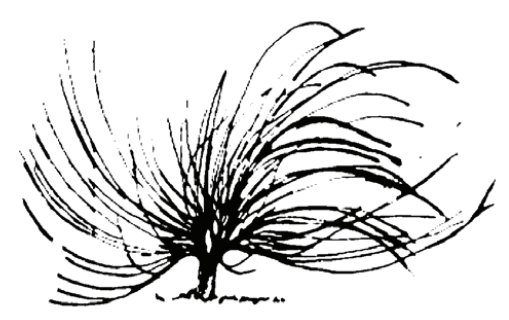

\title{
Las Humanidades Entre las Cuerdas del Neoliberalismo*
}

\author{
Abdiel Rodríguez Reyes ${ }^{1}$ \\ CIFHU-Universidad de Panamá \\ Panamá \\ abdielarleyrodriguez@hotmail.com
}

"El espíritu, como el cuerpo, tiene sus necesidades"

Jean-Jacques Rousseau

\section{Resumen}

Este artículo problematiza la situación de las humanidades en el auge del neoliberalismo. Propone que para comprender el mundo moderno es necesario problematizar e interrelacionar los ámbitos del saber humanístico, científico y tecnológico. También crítica la visión que se tiene de la educación al servicio exclusivo de la sociedad de mercado y las élites financieras.

Palabras clave: humanidades, neoliberalismo, educación integral, mercado, conocimiento

\begin{abstract}
This article problematizes the situation of the humanities in the rise of neoliberalism. It proposes that to understand the modern world, it is necessary to problematize and interrelate humanistic fields of knowledge, science and technology. It is also critical to consider the vision we
\end{abstract}

\section{(c) (1) $(9$}

Recibido: 10 de diciembre de 2014 - Aprobado:18 de agosto de 2015

1 Investigador en la Universidad de Panamá. Becario del CLACSO. Doctorando en la Universidad del País Vasco. 
have of education at the exclusive service of the market society and the financial elites

Keywords: humanities, neoliberalism, education integral, market, knowledge

\section{A modo de introducción}

En el presente artículo, se problematizan algunos elementos que muestran la situación de las humanidades en el auge del neoliberalismo. Asimismo, la premisa que, para comprender el mundo moderno, es necesario problematizar e interrelacionar los ámbitos del saber humanístico, científico y tecnológico para encarar los problemas de nuestro siglo.

Del mismo modo, se critica la visión que se tiene de la educación de estar al servicio exclusivo de la sociedad de mercado y las élites financieras. El breve artículo propone una educación que integre los diversos saberes, implícitamente sugiere la necesidad de una investigación científica sobre el particular.

\section{La pregunta por las humanidades}

La cuestión de las humanidades es un tema amplio y el concepto extenso. El debate contemporáneo en el que se inicia actualmente la sociedad de mercado gira en su utilidad instrumental, el cual debe tomar otra dirección. Omitiendo la utilidad instrumental, ¿cuál es el deber de las humanidades? Para delimitar esta polémica, examinemos la cuestión e identifiquemos dónde han quedado las humanidades, podemos pensar que en medio del neoliberalismo que se consolidó a finales de la década de los setenta. ${ }^{2}$ Una pregunta contemporánea nos llevaría a interrogar por el deber de estas en un mundo globalizado, ${ }^{3}$ su relación con las Ciencias

2 Punto de partida del neoliberalismo, a nivel global, a finales de los setenta. Esta breve historia inicia con Deng Xiaping, Margaret Thatcher y Ronald Reagan. Para una definición de neoliberalismo: "el neoliberalismo es, ante todo, una teoría de prácticas políticas - económicas que afirma que la mejor manera de promover el bienestar del ser humano no consiste en no restringir el libre desarrollo de las capacidades y de las libertades empresariales del individuo dentro de un marco institucional caracterizado por derechos de propiedad fuertes, mercados libres y libertad de comercio" (Harvey, 2007, p. 7).

3 Esta preocupación la encontramos en la Universidad de Panamá, con Luis Pulido Ritter en su ponencia: Humanidades en Tránsito: Retos y preguntas (in) disciplinadas para un mundo en movimiento. Conferencia dictada en el salón Octavio O. Sisnett, el 20 de agosto de 2014 en el marco de la Jornada Académica del Doctorado en Humanidades y Ciencias Sociales. 
Sociales y las Naturales ${ }^{4}$ en la lógica de cómo se organiza nuestro conocimiento. Esto tiene como fondo el tema de la inter-, multi-, trans- y polidisciplinariedad, ya no como un enunciado -muy frecuente en la comunidad de "científicos sociales"-, sino como una necesidad para comprender las complejas transformaciones sociales en curso.

\section{El "deber" de las humanidades}

Para deshilvanar el "deber" es indispensable trabajar sobre el concepto, en este momento el de las humanidades. En este bregar seguimos a Hegel (2009, p. 46), cuando señala que "a los verdaderos pensamientos y a la penetración científica sólo puede llegarse mediante la labor del concepto". Hacer historia del proceso que ha llevado a las humanidades a ocupar el lugar que tienen es prioritario. En términos generales, las humanidades instruyen en el ámbito del conocimiento, su objeto de estudio y eje principal es el ser humano -en todas sus dimensiones-. Por tanto, desde la arqueología hasta los entramados de la mente humana son de interés para un humanista. A partir de la existencia de los centros de conocimiento y las universidades, a las humanidades le ha correspondido el aprendizaje de las buenas artes y los estudios clási$\cos .^{5}$ ¿Qué ha sido de esto? Como diría Rousseau: El espíritu, como el cuerpo, tiene sus necesidades.

En el mundo griego, La Academia, El Liceo y El Jardín eran pequeños espacios para la élite de la época que tenían acceso a estas temáticas. Un caso particular era el de Sócrates, que enseñaba por las calles de Atenas; incluso su última clase la dio en la cárcel, antes de tomarse la cicuta. El Medievo estuvo marcado por la escolástica, el estudio de la medicina, el arte, las leyes y los cánones. La situación toma otro rumbo cuando la Iglesia es acusada y pierde fuerzas. En el siglo XVI decae la escolástica, en el momento en que la reflexión moderna empieza a desplegarse con fuerza durante varios siglos. A partir del siglo XIX, las universidades se convierten en la parte vertebral de la sociedad, timoneadas por las demandas del sector industrial. Del siglo xx a los inicios del XXI, las

4 En la ceremonia inaugural del Ciclo Académico 2012 de la Facultad Latinoamericana de Ciencias Sociales, sede académica de México, Roger Bartra habla de dilemas de las Ciencias Sociales, estas quedan entre las Humanidades y la Ciencia. Tienen la difícil tarea de dar respuesta a ambos bandos.

5 Abbagnano (2007, p. 563) lo definiría como "el reconocimiento del valor humano de las letras clásicas". 
humanidades comienzan a ser un obstáculo para los gobiernos neoliberales, peones de la sociedad de mercado; de los programas curriculares se disminuyen los contenidos humanísticos (filosofia ${ }^{6}$ arte, ética e historia, entre otros.). Esto se acentúa cuando los gobiernos abiertamente neoliberales promueven una educación, solo al servicio de las necesidades de la sociedad de mercado. ${ }^{7}$ Lo que requería este tipo de sociedad era a un buen empleado, obediente, eficiente, productivo y competitivo; por tanto, se educa en esa dirección. De modo extraño, la educación se ha atomizado en esa fórmula, lo demás ha quedado marginado. Tal es el caso de cuestiones vitales para una educación integral.

¿No es el valor de la vida y el estudio de los clásicos y las artes lo que estamos perdiendo? Los clásicos y las artes han sido reemplazados por una civilización del espectáculo ${ }^{8}$ que resta importancia a lo que sí tiene fundamento, material-sustantivo para la vida. Lo que promueve la sociedad de mercado es lo contrario, ya que todo debe ser visto como mercancía, ${ }^{9}$ como un fetiche.

Hemos perdido el valor de la vida misma e implementado el del cambio, donde solo importa lo material. En este sentido, como se perdió el mérito de la vida, también se perdió la importancia hacia los otros. Las muestras empíricas están registradas en cualquier periódico mediamente informado, acerca de los altos niveles de violencia y el poco valor hacia el otro. ${ }^{10}$

En cuanto al valor de lo humano, -la vida, sustento material-sustantivo de las humanidades-, si no tenemos una concepción de referencia, perderemos el rumbo al no tener la capacidad de cohabitar con el

6 En el caso de Filosofía, véase el artículo: Rodríguez, A. (2014). "Políticas Educativas: La Filosofía en los programas de educación media”, en Revista Panameña de Política.

7 Sobre este aspecto véase el interesante artículo de Benedetti, Giovanna. "La globalización de la educación y el fin de la historia" (A propósito de la eliminación de la cátedra de Historia de las relaciones de Panamá con Estados Unidos), en Temas de Nuestra América.

8 Siguiendo a Guy Debord (1967), "El espectáculo no es un conjunto de imágenes, sino una relación social entre personas mediatizada por imágenes” (p.4), y estas imágenes no necesariamente son la realidad. Seguimos con Debord: "El espectáculo se presenta como una enorme positividad indiscutible e inaccesible. No dice más que lo que aparece es bueno, lo que es bueno aparece". La actitud que exige por principio es esta aceptación pasiva que ya ha obtenido por su forma de aparecer sin réplica, por su monopolio de la apariencia" (:12).

9 Sobre este punto recomiendo el texto de Wolfgang Fritz Haug "Publicidad y consumo", en Critica de la estética de mercancías.

10 Las dos guerras son ejemplo del lado oscuro de la humanidad. El holocausto muestra la banalidad del ser humano, de cómo se está perdiendo el valor por la vida, y cómo podemos matar a otro, a miles, a millones por presupuestos de superioridad. Casos marginales de pandillerismo y todas las variantes de violencia son evidencia de cómo se ha perdido el valor humano. 
"otro" de forma coherente. Esto es una primera aproximación al deber de las humanidades. La manera más democrática es regresar al debate, a la agenda pública.

En el encuentro, en la vida y en la reciprocidad con el "otro", la vida es el norte en la fundamentación de las humanidades, así como el estudio de los clásicos y el arte. Si esto no es claro, nos dirigimos a una nueva barbarie, lo que llama Boaventura de Sousa Santos (2009) como fascismo social; lo que se vivió con el exterminio de gran parte de los nativos en el encuentro de Abya Yala, Europa en 1492 y con el totalitarismo del siglo Xx (Arendt, 2013).

Buena parte de lo que ocurre indica que estamos ante la puerta de una crisis civilizatoria. ${ }^{11} \mathrm{Al}$ menos la occidental como civilización hegemónica. Mészáros (2009) diría que la crisis estructural es la forma de organización, en torno al capital, con este horizonte se puede perder el rumbo de unas humanidades con capacidad de encarar los problemas de este siglo; sino tenemos claro, conceptualmente, las batallas que hay que librar, perderemos la guerra contra el espíritu de la época.

Otras cuestiones que deben abordar las humanidades son las dimensiones ciudadanas y la emancipación que sería una segunda aproximación al "deber" de las humanidades bajo la fiel lectura de la tradición literaria de estas; las cuales, hay que analizar y poner en orden; es decir, contextualizar a nuestra particularidad como región y a nuestras condiciones culturales. No se trata de renunciar a las demandas y los debates contemporáneos ${ }^{12}$ globales ni quedar atrapados en el pasado o las abstracciones y generalizaciones, sino asumir la difícil tarea de no aceptar el espíritu de la época sin mayores reservas ni las limitaciones focales de concentrarse en un punto ni que un caso puede representar el universo.

No se trata de especular sobre lo que "debe ser" (futurismo) o "cómo deben ser" las cosas, no se trata de dar recetas. Las humanidades tienen un compromiso que no se ha materializado por el desconocimiento de su propio desarrollo histórico y por estar ausente de la discusión en los puestos de mando, donde se toman las decisiones de

11 "La noción de crisis civilizatoria es importante porque con ella se quiere enfatizar que estamos asistiendo al agotamiento de un modelo de organización económica, productiva y social, con sus respectivas expresiones en el ámbito ideológico, simbólico y cultural” (Vega, 2009)

12 Por ejemplo, Pablo González Casanova enfatiza en el estudio de las tecnociencias y las ciencias de la complejidad para discernir las nuevas formas de comprender la organización del saber. 
las políticas públicas. La educación debe pensarse de forma integral: tecnológica, científica y humanísticamente.

Son las instituciones de la globalización, la Organización Mundial del Comercio, el Fondo Monetario Internacional y el Banco Mundial, las que nos indican cuáles son nuestras necesidades; donde las humanidades no forman parte de las prioridades del mundo moderno, no tienen cabida en las prioridades educativas de muchos gobiernos y, por otra parte, se presentan como ajenas a la cotidianidad del ser humano.

Al plantear el problema, la cuestión trata de la falta de educación como un factor crucial, lámese humanista, o una educación integral que ayude al humano a humanizarse. No solo darle prioridad a lo científico, sino a lo tecnológico como corolario de nuestras necesidades para lograr un desarrollo pleno como nación.

El problema se ha acentuado en la visión simplista de que cualquier crítica a la educación al servicio de la sociedad de mercado es atentar contra el desarrollo del país. También es necesario desarrollar un ethos (Hartmann, 1950) acorde con las propias necesidades y principios que rigen una convivencia plena con el entorno social y natural (Castro, 2007).

\section{A modo de conclusión}

Si abordamos este problema desde el sentido común, es complejo. El problema es que en estos últimos 50 años no se ha realizado, en nuestro medio, una investigación sistemática que analice si la falta de educación integral (científica, técnica, humanística) es un problema para la realización del ser humano. Lo que buscamos es, como diría Antonio Gramsci (1977, p. 389), que el individuo pueda "ser guía de sí mismo en vez de aceptar la impronta puesta desde afuera". Como lo expone la idea kantiana de la ilustración: que cada cual piense con su propia cabeza.

- Conferencia en el XIV Congreso de la Asociación Centro Americana de Sociología (22 al 26 de septiembre de 2014, Chiriquí, Panamá) 


\section{Referencias bibliográficas}

Abbagnano, N. (2007), Diccionario de Filosofía. México: FCE. Arendt, H. (2013). Los orígenes del totalitarismo. Madrid: Alianza.

Benedetti, G. (2014). "La globalización de la educación y el fin de la historia" (A propósito de la eliminación de la cátedra de Historia de las relaciones de Panamá con Estados Unidos), en Temas de Nuestra América, núm. 387, julio.

Castro, G. (2007). "Sostenible por lo humano", en El agua entre los mares, Panamá, Fundación Ciudad del Saber.

De Sousa Santos, B. (2009). Sociología jurídica crítica: Para un nuevo sentido común en el derecho. Madrid: Trotta.

Fritz Haug, W. (1993). "Publicidad y consumo", en Crítica de la estética de mercancías. México, FCE.

Gramsci, A. (1977). Antología, II de los años 1926-1937. México: siglo XXI, $\mathrm{p}-389$

Gramsci, A. (1970), Introducción a la Filosofía de la praxis. Barcelona: Ediciones Península.

Hartmann, N. (1950). "El ethos de la personalidad Der Ethos der Persönlichkeit”, en Mendoza, Actas del Primer Congreso Nacional de Filosofía, Buenos Aires, Universidad Nacional de Cuyo, tomo I, abril, pp. 300-315.

Harvey, D. (2007). Breve historia del neoliberalismo. Madrid: Akal.

Hegel, G. W. (2009). Fenomenología del espiritu. México: FCE.

Mészáros, I. (2009). La crisis estructural del capital. Venezuela: Ministerio del Poder Popular para la Comunicación y la Información.

Rodríguez Reyes, A. (2014) Políticas educativas: La Filosofía en los programas de educación media. Revista Panameña de Política, 17, 91-97.

Vega, R. (2009). “Crisis civilizatoria”, en Herramienta, núm. 42, octubre, disponible en http://www.herramienta.com.ar/revista-herramienta-n-42/ crisis-civilizatoria 